\title{
АНАЛИЗ ВЛИЯНИЯ КОМПОНЕНТОВ СТРАТЕГИЧЕСКОГО МЕНЕДЖМЕНТА НА ЭФФЕКТИВНОСТЬ И РЕЗУЛЬТАТИВНОСТЬ ДЕЯТЕЛЬНОСТИ МАЛОГО И СРЕДНЕГО БИЗНЕСА
}

\author{
(c) 2021 Кузнецова Мария Олеговна \\ старший преподаватель Департамента менеджмента и инноваций \\ Факультета «Высшая школа управления» \\ Финансовый университет при Правительстве Российской Федерации, Россия, Москва \\ E-mail:MOKuznetsova@fa.ru
}

В статье были рассмотрены условия и факторы развития предпринимательства в России. На основе обзора российской и зарубежной литературы, а также экспертного опроса были выявлены основные инструменты стратегического менеджмента, которые позволяют повысить уровень эффективности и результативности деятельности субъектов малого и среднего предпринимательства (МСП). Даны некоторые предложения по развитию предпринимательства в России.

Ключевые слова: предпринимательство, бизнес, условия развития предпринимательства, стратегическое предпринимательство, корреляционно-регрессионный анализ, инструменты стратегического менеджента.

\section{Введение}

Развитие малого и среднего предпринимательства является важным условием для наращивания налоговой базы, создания рабочих мест и решения социальных проблем. Согласно результатам исследований, рост количества субъектов малого и среднего предпринимательства способствует росту конкуренции в экономике. Вместе с тем, важным преимуществом МСП является их инновационность. Согласно исследованиям, проведенным в США (An Analysis of Small Business Patents by Industry and Firm Size) в секторе МСП создается в 16 раз больше патентов в расчете на одного работника, чем в крупном бизнесе [9].

Развитие малого и среднего предпринимательства, вовлечение населения в занятие предпринимательством, открытие своего бизнеса является важнейшей задачей в целях обеспечения роста конкуренции и развития экономики. Однако, следует отметить, что в России для желающих заниматься предпринимательской деятельностью сложившиеся условия нельзя назвать в полной мере привлекательными. В этой связи многие бизнес-планы и стратегии остаются нереализованными. Вместе с тем многие граждане в России не располагают необходимым уровнем доходов для открытия своего собственного дела, а также не в полной мере осведомлены о государственных мерах поддержки субъектов малого и среднего предпринимательства. Также следует отметить, что существуют определенные проблемы в обеспечении эффективности деятельности субъектов малого и среднего предпринимательства [9], [11].

Факторы и компоненты стратегического планирования, влияющие на эффективность и результативность субъектов малого и среднего предпринимательства

Интенсивность вовлечения граждан в занятие предпринимательской деятельностью во многом обусловлена отношением населения к предпринимательству. В Национальном отчете «Глобальный мониторинг предпринимательства» Россия 2018/2019 приведены основные показатели для измерения общественного отношения к предпринимательству в рамках модели GEM (Global Entrepreneurship Monitor, GEM) [9], [16]. Данные показатели представлены в таблице 1.

Таким образом, существует множество факторов, влияющих на отношение граждан к предпринимательству, которые выражены в ощущении престижности предпринимательства; наличии в окружении знакомых, имеющих свое собственное дело; легкости и доступности открытия нового бизнеса. Вместе с тем, следует отметить важность наличия условий для развития предпринимательства в стране.

В Национальном отчете «Глобальный мониторинг предпринимательства» Россия 2018/2019 [9] представлены результаты исследо- 
Таблица 1. Социальные ценности и восприятия предпринимателей

\begin{tabular}{|c|c|}
\hline Показатель & Основные характеристики \\
\hline $\begin{array}{l}\text { Привлекательность предпри- } \\
\text { нимательства с карьерной } \\
\text { точки зрения }\end{array}$ & $\begin{array}{l}\text { Привлекательность предпринимательства обусловлена тем насколько оно } \\
\text { может повысить престиж индивида в обществе, добиться положения в обще- } \\
\text { стве, достичь финансового успеха, самореализоваться }\end{array}$ \\
\hline $\begin{array}{l}\text { Престижность предпринима- } \\
\text { тельства }\end{array}$ & $\begin{array}{l}\text { Если предприниматель пользуется положением в обществе, то ему легче } \\
\text { получить помощь инвесторов }\end{array}$ \\
\hline $\begin{array}{l}\text { Внимание СМИ к успешным } \\
\text { предпринимателям }\end{array}$ & $\begin{array}{l}\text { Публикация в СМИ историй успешных предпринимателей позволяет повы- } \\
\text { сить общую привлекательность предпринимательства }\end{array}$ \\
\hline $\begin{array}{l}\text { Наличие в окружении знако- } \\
\text { мых, которые за последние } \\
\text { два года открыли бизнес }\end{array}$ & $\begin{array}{l}\text { Воздействием к открытию собственного бизнеса может служить наличие } \\
\text { опыта открытия бизнеса в прошлом или родственники/знакомые, которые } \\
\text { занимаются предпринимательством }\end{array}$ \\
\hline $\begin{array}{l}\text { Легкость и доступность от- } \\
\text { крытия нового бизнеса }\end{array}$ & Насколько легко открыть новый бизнес по мнению населения \\
\hline $\begin{array}{l}\text { Предпочтение общих стан- } \\
\text { дартов жизни }\end{array}$ & Мнение среди людей о едином стандарте жизни \\
\hline Решение социальных проблем & $\begin{array}{l}\text { Мнение в обществе о том насколько часто встречаются компании, которые } \\
\text { способны решить различные социальные проблемы в стране }\end{array}$ \\
\hline
\end{tabular}

Источник: составлено автором по материалам [9].

вания в рамках проекта GEM в части социальноэкономических факторов, оказывающих влияние на предпринимательскую активность в обществе [9]:

1. Финансовая поддержка. Доступность грантов и субсидий для развития новых фирм. Наличие заемного и собственного капитала для открытия бизнеса.

2. Политика государства. В рамках данного фактора рассматриваются особенности государственного регулирования сферы МСП, налогообложения и т.д.

3. Государственные программы. Наличие государственных программ поддержки новых и развивающихся фирм. Эффективность функционирования государственных служб, взаимодействующих с субъектами малого и среднего предпринимательства.

4. Уровень образования и профессиональной подготовки. Включенность подготовки по созданию и ведению собственного бизнеса в систему общего, среднего и высшего образования.

5. Внедрение научных разработок. Наличие научно-технических разработок, которые способствуют созданию возможностей для открытия нового бизнеса и развития существующего бизнеса.

6. Наличие коммерческой и профессиональной инфраструктуры. Уровень развития коммерческих и юридических служб, оказывающих поддержку субъектам МСП.

7. Открытость рынка. Наличие барьеров вхождения на рынок.
8. Доступность к физической инфраструктуре. Доступность средств связи (телефонная связь, почта, Интернет); наличие транспорта; качества предоставляемых коммунальных услуг.

9. Уровень культурных и социальных норм. Наличие и уровень развитие социальнокультурных норм, которые побуждают граждан к занятию предпринимательством.

Вместе с тем, важно учитывать современные тенденции функционирования мировой экономики в условиях пандемии COVID-19. Серьезное влияние оказала пандемия COVID-19 на ведение бизнеса во всем мире. В этой связи, во многих странах были введены меры поддержки субъектов МСП в условиях пандемии COVID-19. Так в Москве были введены меры поддержки по четырем направлениям [6]:

- субсидии для предприятий;

- помощь с оплатой аренды и выкупом недвижимости у города;

- помощь инновационным компаниям;

- поддержка экспортеров.

На сайте Мэра Москвы [6] подробно представлены данные направления поддержки, а также условия получения каждого вида поддержки. Созданные условия для развития субъектов МСП в условиях пандемии также являются важным аспектом в формировании предпринимательской привлекательности в стране.

В современной российской и зарубежной литературе можно выделить множество факторов, которые оказывают существенное влияние на эффективность и результативность предпри- 
нимательства. Следует отметить одну из современных концепций предпринимательства стратегическое предпринимательство. Впервые концепция «стратегическое предпринимательство» было представлено в исследованиях по менеджменту и предпринимательству М.А.Хиттом в 2001 г. в журнале Strategic Management Journal [3], [14]. В данном научном труде концепция «стратегическое предпринимательство» было рассмотрено с позиции научной дисциплины, которая объединяет в себе предпринимательство и стратегический менеджмент [3].

В результатах исследования, представленных в статье Л.А.Иввонен и Г.В.Широковой «Стратегическое предпринимательство: сущность и основные направления исследований», рассматривается влияние стратегического предпринимательства на результаты деятельности фирмы [3]:

- объединение стратегического менеджмента и предпринимательства положительно влияют на результаты деятельности фирмы;

- предпринимательская инициативность, принятие риска, эффективная организационная структура, выстроенная корпоративная культура (элементы внутренней среды фирмы) положительно влияют на рост и прибыльность компании;

- либеральная экономическая политика, объединение совместных инноваций и страте- гического предпринимательства также положительно влияют на эффективность и результативность компании.

В настоящей статье была предпринята попытка выявить влияние элементов стратегического менеджмента по формированию стратегии на эффективность и результативность субъектов МСП. Исследование проводилось в два этапа: качественный и количественный [4], [5].

На качественном этапе исследования на основе обзора российской и зарубежной литературы были выявлены основные инструменты стратегического менеджмента, которые направлены на формирование стратегий, и оказывают существенное влияние на эффективность и результативность деятельности субъектов малого и среднего предпринимательства [4], [5]. Результаты качественного этапа исследования представлены в таблице 2.

Далее был проведен экспертный опрос 63 субъектов малого и среднего предпринимательства, который позволил выявить наиболее существенные инструменты стратегического менеджмента для достижения показателей эффективности и результативности фирм. В таблице 3 представлены результаты опроса субъектов МСП.

Таким образом, наиболее значимыми инструментами стратегического менеджмента для достижения показателей эффективности и ре-

Таблица 2. Инструменты стратегического менеджмента, влияющие на эффективность и результативность МСП

\begin{tabular}{|c|l|}
\hline $\begin{array}{c}\text { Условное } \\
\text { обозначение }\end{array}$ & \multicolumn{1}{|c|}{ Инструменты стратегического менеджмента } \\
\hline$x_{1}$ & SWOT-анализ \\
\hline$x_{2}$ & РEST-анализ \\
\hline$x_{3}$ & Анализ пяти сил М.Портера \\
\hline$x_{4}$ & Портфельный анализ \\
\hline$x_{5}$ & Дизайн-мышление \\
\hline$x_{6}$ & Построение цепочки создания ценности \\
\hline$x_{7}$ & Определение стратегии в соответствии с этапом развития жизненного цикла продукта \\
\hline$x_{8}$ & Управление рисками реализации стратегии \\
\hline$x_{9}$ & Определение стратегии фирмы в соответствии с типологией эталонных стратегий \\
\hline$x_{10}$ & $\begin{array}{l}\text { Определение стратегии фирмы в соответствии с типологией конкурентных стратегий по } \\
\text { М.Портеру }\end{array}$ \\
\hline$x_{11}$ & Формирование КРІ фирмы \\
\hline$x_{12}$ & Использование бенчмаркинга \\
\hline$x_{13}$ & Анализ стейкхолдеров фирмы \\
\hline$y$ & Достижение показателей эффективности и результативности фирмы \\
\hline
\end{tabular}

Источник: составлено по материалам исследования [1], [2], [7], [8], [10], [12], [13], [15]. 
Таблица 3. Результаты опроса субъектов МСП по выявлению наиболее существенных инструментов стратегического менеджмента, оказывающих влияние на достижение показателей эффективности и результативности фирм

\begin{tabular}{|l|c|}
\hline \multicolumn{1}{|c|}{ Инструменты стратегического менеджмента } & $\begin{array}{c}\text { Доля } \\
\text { опрошенных (\%) }\end{array}$ \\
\hline SWOT-анализ & 48 \\
\hline PEST-анализ & 58 \\
\hline Анализ пяти сил М.Портера & 71 \\
\hline Портфельный анализ & 38 \\
\hline Дизайн-мышление & 41 \\
\hline Построение цепочки создания ценности & 60 \\
\hline Определение стратегии в соответствии с этапом развития жизненного цикла продукта & 65 \\
\hline Управление рисками реализации стратегии & 37 \\
\hline Определение стратегии фирмы в соответствии с типологией эталонных стратегий & 32 \\
\hline $\begin{array}{l}\text { Определение стратегии фирмы в соответствии с типологией конкурентных стратегий по } \\
\text { М.Портеру }\end{array}$ \\
\hline Формирование КРІ фирмы & 45 \\
\hline Использование бенчмаркинга & 37 \\
\hline Анализ стейкхолдеров фирмы & 49 \\
\hline
\end{tabular}

Источник: составлено автором

зультативности фирм являются анализ пяти сил М.Портера, определение стратегии в соответствии с этапом развития жизненного цикла продукта, построение цепочки создания ценности.

В рамках количественного этапа исследования был проведен корреляционнорегрессионный анализ, который позволил выделить наиболее значимые инструменты стратегического менеджмента для достижения показателей эффективности и результативности субъектов малого и среднего предпринимательства [4], [5]. Корреляционно-регрессионный анализ был проведен с помощью программного пакета STATISTICA.

Проведенный корреляционный анализ позволил выбрать наиболее значимые инструменты стратегического менеджмента для достижения показателей эффективности и результативности субъектов малого и среднего предпринимательства, а также исключить те инструменты стратегического менеджмента, для которых наблюдается высокий коэффициент мультиколлинеарности $(>0,8)$ [4], [5]. Результаты корреляционного анализа представлены в таблице 4.

Корреляционный анализ позволил отобрать наиболее значимые инструменты стратегического менеджмента для достижения показателей эффективности и результативности субъектов малого и среднего предпринимательства (таблица 5).

Далее был проведен регрессионный анализ влияния инструментов стратегического менеджмента на достижение показателей эффективности и результативности субъектов малого и среднего предпринимательства по формуле множественной регрессии (формула 1) [4], [5].

$$
\begin{array}{r}
y=\beta_{0}+\beta_{1} x_{1}+\beta_{3} x_{3}+\beta_{4} x_{4}+\beta_{5} x_{5}+\beta_{6} x_{6}+\beta_{7} x_{7} \\
+\beta_{9} x_{9}+\beta_{12} x_{12}
\end{array}
$$

где $y$ - зависимая переменная (эффективность внедрения корпоративных инноваций);

$\beta_{I}$ - нестандартизированный коэффициент.

Результаты регрессионного анализа представлены в таблице 6.

Полученное уравнение регрессии можно считать статистически значимым, т.к. коэффициент детерминации $R^{2}=0,975$ (значение близко к 1). Это доказывает высокое качество полученной модели. Уровень значимости полученной регрессионной модели составляет $p<0,05$, что также демонстрирует точность и высокое качество полученной модели. Следует отметить, что наиболее значимыми инструментами стратегического менеджмента, оказывающими существенное влияние на достижение показателей эффективности и результативности, являются анализ пяти сил М.Портера $(\beta=0,680)$; опреде- 
Таблица 4. Результаты корреляционного анализа

\begin{tabular}{|c|c|c|c|c|c|c|c|c|c|c|c|c|c|c|}
\hline & $y$ & $x_{1}$ & $x_{2}$ & $x_{3}$ & $x_{4}$ & $x_{5}$ & $x_{6}$ & $x_{7}$ & $x_{8}$ & $x_{9}$ & $x_{10}$ & $x_{11}$ & $x_{12}$ & $x_{13}$ \\
\hline$y$ & 1,000 & 0,829 & 0,139 & 0,790 & 0,376 & $-0,509$ & $-0,327$ & 0,737 & $-0,038$ & $-0,435$ & 0,000 & 0,000 & 0,744 & $-0,225$ \\
\hline$x_{1}$ & 0,829 & 1,000 & 0,000 & 0,612 & 0,694 & $-0,505$ & $-0,492$ & 0,480 & 0,150 & $-0,342$ & 0,000 & 0,190 & 0,464 & $-0,570$ \\
\hline$x_{2}$ & 0,139 & 0,000 & 1,000 & 0,127 & 0,106 & 0,494 & 0,173 & 0,161 & 0,345 & 0,095 & 0,000 & $-0,102$ & 0,144 & 0,418 \\
\hline$x_{3}$ & 0,790 & 0,612 & 0,127 & 1,000 & 0,118 & $-0,575$ & 0,157 & 0,458 & $-0,454$ & $-0,704$ & 0,127 & $-0,310$ & 0,466 & 0,056 \\
\hline$x_{4}$ & 0,376 & 0,694 & 0,106 & 0,118 & 1,000 & $-0,230$ & $-0,539$ & 0,150 & 0,481 & 0,032 & 0,317 & 0,086 & 0,170 & $-0,612$ \\
\hline$x_{5}$ & $-0,509$ & $-0,505$ & 0,494 & $-0,575$ & $-0,230$ & 1,000 & 0,034 & $-0,335$ & 0,119 & 0,150 & $-0,494$ & 0,101 & $-0,412$ & 0,165 \\
\hline$x_{6}$ & $-0,327$ & $-0,492$ & 0,173 & 0,157 & $-0,539$ & 0,034 & 1,000 & $-0,022$ & $-0,429$ & $-0,118$ & 0,345 & $-0,211$ & $-0,079$ & 0,711 \\
\hline$x_{7}$ & 0,737 & 0,480 & 0,161 & 0,458 & 0,150 & $-0,335$ & $-0,022$ & 1,000 & 0,089 & $-0,037$ & 0,161 & 0,132 & 0,065 & 0,162 \\
\hline$x_{8}$ & $-0,038$ & 0,150 & 0,345 & $-0,454$ & 0,481 & 0,119 & $-0,429$ & 0,089 & 1,000 & 0,801 & 0,173 & 0,423 & 0,119 & $-0,154$ \\
\hline$x_{9}$ & $-0,435$ & $-0,342$ & 0,095 & $-0,704$ & 0,032 & 0,150 & $-0,118$ & $-0,037$ & 0,801 & 1,000 & 0,286 & 0,233 & 0,033 & 0,223 \\
\hline$x_{10}$ & 0,000 & 0,000 & 0,000 & 0,127 & 0,317 & $-0,494$ & 0,345 & 0,161 & 0,173 & 0,286 & 1,000 & $-0,408$ & 0,287 & 0,278 \\
\hline$x_{11}$ & 0,000 & 0,190 & $-0,102$ & $-0,310$ & 0,086 & 0,101 & $-0,211$ & 0,132 & 0,423 & 0,233 & $-0,408$ & 1,000 & $-0,059$ & $-0,455$ \\
\hline$x_{12}$ & 0,744 & 0,464 & 0,144 & 0,466 & 0,170 & $-0,412$ & $-0,079$ & 0,065 & 0,119 & 0,033 & 0,287 & $-0,059$ & 1,000 & 0,216 \\
\hline$x_{13}$ & $-0,225$ & $-0,570$ & 0,418 & 0,056 & $-0,612$ & 0,165 & 0,711 & 0,162 & $-0,154$ & 0,223 & 0,278 & $-0,455$ & 0,216 & 1,000 \\
\hline
\end{tabular}

Источник: составлено автором

Таблица 5. Наиболее значимые инструменты стратегического менеджмента для достижения показателей эффективности и результативности субъектов малого и среднего предпринимательства

\begin{tabular}{|c|l|}
\hline $\begin{array}{c}\text { Условное } \\
\text { обозначение }\end{array}$ & \multicolumn{1}{|c|}{ Инструменты стратегического менеджмента } \\
\hline$x_{1}$ & SWOТ-анализ \\
\hline$x_{3}$ & Анализ пяти сил М.Портера \\
\hline$x_{4}$ & Портфельный анализ \\
\hline$x_{5}$ & Дизайн-мышление \\
\hline$x_{6}$ & Построение цепочки создания ценности \\
\hline$x_{7}$ & Определение стратегии в соответствии с этапом развития жизненного цикла продукта \\
\hline$x_{9}$ & Определение стратегии фирмы в соответствии с типологией эталонных стратегий \\
\hline$x_{12}$ & Использование бенчмаркинга \\
\hline
\end{tabular}

Источник: составлено автором 
Таблица 6. Регрессионный анализ влияния инструментов стратегического менеджмента на достижение показателей эффективности и результативности субъектов малого и среднего бизнеса

\begin{tabular}{|l|c|c|}
\hline \multicolumn{1}{|c|}{ Независимый показатель } & $\begin{array}{c}\text { Стандартизиро- } \\
\text { ванный коэффи- } \\
\text { циент }\end{array}$ & $\begin{array}{c}\text { Нестандартизиро- } \\
\text { ваннй коэффи- } \\
\text { циент }\end{array}$ \\
\hline Свободный член & & 1,543 \\
\hline SWOT-анализ & 0,073 & 0,081 \\
\hline Анализ пяти сил М.Портера & 0,680 & 0,619 \\
\hline Портфельный анализ & $-0,017$ & $-0,013$ \\
\hline Дизайн-мышление & 0,055 & 0,049 \\
\hline Построение цепочки создания ценности & 0,399 & 0,494 \\
\hline $\begin{array}{l}\text { Определение стратегии в соответствии с этапом развития жизнен- } \\
\text { ного цикла продукта }\end{array}$ & 0,447 & 0,022 \\
\hline $\begin{array}{l}\text { Определение стратегии фирмы в соответствии с типологией эта- } \\
\text { лонных стратегий }\end{array}$ & 0,032 & $-0,046$ \\
\hline Использование бенчмаркинга & $-0,044$ & \\
\hline $\begin{array}{l}\text { Итоги регрессии для зависимой переменной: } \\
R=0,988 \\
R^{2}=0,975 \\
\text { Скорректированный R2=0,963 } \\
F=4,932 \\
\text { р } 0,000 \\
\text { Стандартная ошибка оценки: 0,173 }\end{array}$ & & \\
\hline
\end{tabular}

Источник: составлено автором

лении стратегии в соответствии с этапом развития жизненного цикла продукта $(\beta=0,447)$; построение цепочки создания ценности $(\beta=0,399)$.

Регрессионная модель влияния инструментов стратегического менеджмента на достижение показателей эффективности и результативности субъектов малого и среднего предпринимательства имеет следующий вид (формула 2):

$y=1,543+0,081 x_{1}+0,619 x_{3}-0,013 x_{4}+0,049 x_{5}$ $+0,494 x_{6}+0,518 x_{7}+0,022 x_{9}-0,046 x_{12}$

Полученная регрессионная модель позволяет прогнозировать насколько будут достигнуты показатели эффективности и результативности МСП в зависимости от качества использования инструментов стратегического менеджмента в предпринимательской деятельности.

Таким образом, представители субъектов малого и среднего бизнеса в целом отмечают важность использования в предпринимательской деятельности инструментов стратегического менеджмента. Однако, некоторым инструментам уделяется достаточно мало внимание, что является серьезным упущением со стороны предпринимателей. В этой связи необходимо отметить необходимость повышения грамотности населения в части предпринимательства, важность изучения ими таких дисциплин, как менеджмент, стратегический менеджмент и риск-менеджмент, что, несомненно, позволит повысить эффективность и конкурентоспособность бизнеса. Вместе с тем, возникает необходимость в совершенствовании государственной политики в области поддержки и развития МСП.

\section{Выводы}

В статье были проанализированы условия развития предпринимательства, основные меры поддержки субъектов малого и среднего бизнеса, рассмотрены основные меры поддержки Правительства города Москвы субъектов малого и среднего предпринимательства в период пандемии COVID-19.

Также была рассмотрена современная концепция стратегического предпринимательства, которая подразумевает сочетание стратегического менеджмента и предпринимательства.

Корреляционно-регрессионный анализ по- 
зволил выявить наиболее значимые инструменты стратегического менеджмента для повышения уровня эффективности и результативности субъектов МСП.

Предложенные меры повышения уровня эф- фективности и результативности субъектов малого и среднего предпринимательства позволят повысить конкурентоспособность МСП и будут являться предметом для дальнейших исследований.

Статья подготовлена по результатам исследований, выполненных за счет бюджетных средств по государственному заданию Финуниверситета.

\section{Библиографический список}

1. Асадли, Н.И. Методы формирования стратегий промышленных предприятий в цифровой экономике: специальность 08.00.05 «Экономика и управление народным хозяйством»: диссертация на соискание ученой степени кандидата экономических наук / Асадли Ниджат Ибрагимович; МГИМО университет. - Москва, 2021. - 177 с. - Библиогр.: с. 154-177.

2. Домащенко, Д. В. Управление рисками в условиях финансовой нестабильности / Д. В. Домащенко, Ю. Ю. Финогенова. - Москва: Магистр, ИНФРА-М Издательский Дом, 2015. - 240 с. - 1000 экз. - ISBN 978-5-97760138-2.

3. Иввонен, Л.А., Широкова, Г. В. Стратегическое предпринимательство: сущность и основные направления исследований / Л.А. Иввонен, Г. В.Широкова // Вестник Санкт-Петербургского университета. Менеджмент. 2016. - № 4. - С. 21-53. - ISSN 1605-7953.

4. Кузнецова, М.О. Риски внедрения корпоративных инноваций промышленных компаний: результаты эмпирического исследования / М. О. Кузнецова // Стратегические решения и риск-менеджмент. - 2021. - № 1 . Том 12. - С. 82-91. - ISSN 2618-947X.

5. Кузнецова, М.О. Стратегическая устойчивость промышленных компаний: подходы к пониманию и анализ рисков / М. О. Кузнецова // Стратегические решения и риск-менеджмент. - 2020. - № 2. Том 11. - С. 196-205. - ISSN 2618-947X.

6. Меры поддержки бизнеса / Официальный сайт Мэра Москвы // URL: https://www.mos.ru/city/projects/ covid-19/business/. - (дата обращения 19.08.2021).

7. Метод SWOT-анализа в стратегическом управлении / POWERBRANDING // URL: http://powerbranding.ru/ biznes-analiz/swot/. - (дата обращения: 20.08.2021).

8. Модель анализа пяти конкурентных сил Майкла Портера / POWERBRANDING // URL: http://powerbranding. ru/biznes-analiz/porter-model/. - (дата обращения: 20.08.2021).

9. Национальный отчет «Глобальный мониторинг предпринимательства» России 2018/2019 гг. / Высшая школа менеджмента СПБГУ // URL: https://gsom.spbu.ru/files/folder_17/otchet_fin_rgb.pdf. - (дата обращения 15.09.2021 г.).

10. Поскочинова, О. Организационно-методические подходы к выявлению операционных рисков производственной компании / О. Поскочинова // РИСК: Ресурсы, Информация, Снабжение, Конкуренция. - 2014. № 2. - c. 255-259. - ISSN онлайновой версии 0130-3848. - Текст: электронный. - DOI отсутствует. - URL: http://www.risk-online.ru/archive/ (дата обращение: 20.08.2021).

11. Титов, Б. Ю. Сектор малого и среднего предпринимательства: Россия и Мир / Б. Ю. Титов // Институт экономики роста им. Столыпина П.А.. - URL: https://stolypin.institute/wp-content/uploads/2018/07/issledovanieier-msp-27.07.18.pdf. - (дата обращения 15.09.2021 г.).

12. GE McKinsey Matrix. - Текст: электронный // Strategic Management Insight: официальный сайт. - 2018. - URL: https://www.strategicmanagementinsight.com/tools/ge-mckinsey-matrix.html (дата обращения: 20.08.2021).

13. PEST-анализ: разбираем подробно / POWERBRANDING // URL: http://powerbranding.ru/biznes-analiz/pest/. (дата обращения: 20.08.2021).

14. Hitt, M.A., Ireland, R.D., Camp, S.M., Sexton, D.L.Guest Editors' Introduction to the Special Issue. Strategic Entrepreneurship: Entrepreneurial Strategies for Wealth Creation / M. A. Hitt, R. D. Ireland, S. M. Camp, D. L. Sexton // Strategic Management Journal. - 2001. - Vol. 22. - N 6/7. - P. 479-491.

15. The Product Portfolio. - Текст: электронный // BCG: официальный сайт. - 2018. - URL: https://www.bcg.com/ en-ru/ (дата обращения: 20.08.2021).

16. The world's foremost study of entrepreneurship since 1999 / Global Entrepreneurship Monitor // URL: https:// www.gemconsortium.org. - (дата обращения 20.09.2021). 